\title{
RESUMOS DE TESES E DISSERTAÇÕES
}

\section{Relações raciais, Programa Nacional do Livro Didático (PNLD) e livros didáticos de geografia}

\author{
Autor: Wellington Oliveira dos Santos \\ Nível: Mestrado em Educação (PPGE/UFPR) \\ Orientador: Dr. Paulo Vinícius Baptista Silva
}

Neste trabalho efetuamos a análise da presença de personagens negros/as e brancos/as em ilustrações presentes em livros didáticos de Geografia para o $2^{\circ}$ ano do ensino fundamental recomendados pelo Programa Nacional do Livro Didático (PNLD) de 2010. O objetivo foi analisar formas de hierarquização racial que podem estar presentes em livros didáticos de Geografia do ensino fundamental. Utilizamos a teoria da ideologia de J. B. Thompson para a interpretação das formas simbólicas presentes nesses materiais, combinada com procedimentos de análise de conteúdo para organização e interpretação dos dados. Na análise do contexto sócio-histórico de produção e circulação dos livros didáticos consideramos as discussões em torno do racismo brasileiro, além de pesquisas sobre discursos racistas em várias mídias e principalmente aqueles expressos nos livros didáticos. Consideramos também o papel do PNLD, enquanto política educacional, quando trata de combater o racismo na sua avaliação dos livros didáticos, bem como nos Guias e em seus editais. Para a análise quantitativa, inserida na análise formal das formas simbólicas, foi verificada uma amostra de 9 livros didáticos de Geografia para o $2^{\circ}$ ano do ensino fundamental, da qual foram analisados 3.217 personagens em ilustrações. Com o auxílio do programa computacional Statistical Package for Social Sciences 17 (SPSS) e de categorias pré-determinadas para organização e análise dos dados, contamos 1.929 personagens brancos e 663 personagens negros, o que indica uma taxa de branquidade de 2,9 personagens brancos para cada personagem negro da amostra. Considerando a análise do contexto de produção e circulação dos livros didáticos de Geografia e a análise formal efetuada, argumentamos que, apesar das denúncias de pesquisas anteriores com livros didáticos, da mobilização do movimento negro, da criação de políticas educacionais com foco na valorização da população negra e das exigências dos editais do PNLD/2010, permanece nos livros didáticos o discurso racista, que hierarquiza brancos e negros. Os livros didáticos de Geografia continuam veiculando em suas ilustrações discurso que universaliza a condição do branco como representante da espécie humana, característica marcante nas vinhetas relacionadas à construção do saber científico; via de regra estabelecem os personagens brancos como interlocutores dos textos, ao mesmo tempo estigmatiza personagem negro ao utilizá-lo como personagem típico de espaços de miséria. Em comparação com outras pesquisas, algumas formas não hierarquizadas na apresentação de personagens negros e brancos foram observadas, como a presença de personagens negros em contextos familiares e em atributos de valorização. Observamos que a inclusão de personagens negros pode ser feita pela banalização das desigualdades existentes entre negros e brancos, ou utilizando personagens negros nas capas dos livros didáticos sem modificações similares no conteúdo interno (que interpretamos como forma de dissimulação das desigualdades). Comparamos os resultados encontrados em nossa pesquisa com resultados de estudos com livros didáticos e outros sobre mídia em geral, e também pesquisas com livros didáticos de Geografia, apontando convergências e divergências. Realizamos uma discussão acerca do que o PNLD determina em seus critérios de combate ao racismo e valorização dos negros em seus editais, e o que os livros didáticos apresentam, buscando apreender até que ponto as políticas educacionais de combate ao racismo nos livros didáticos têm resultados nos livros didáticos de Geografia.

Palavras-chave: Relações raciais; Discurso racista; Livros didáticos de Geografia; Programa Nacional do Livro Didático. 


\title{
RESUMOS DE TESES E DISSERTAÇÕES
}

\section{Decisões judiciais e valorização dos profissionais do magistério}

\author{
Autor: Ludimar Rafanhim \\ Nível: Mestrado em Educação (PPGE/UFPR) \\ Orientadora: Dra. Andréa Barbosa Gouveia
}

Decisões judiciais e valorização dos profissionais do magistério é uma pesquisa que abrange decisões judiciais envolvendo profissionais do magistério do município de Curitiba entre os anos 2002 e 2010. O objetivo da investigação foi verificar se as decisões prolatadas nas ações ajuizadas individual ou coletivamente por docentes da rede municipal de educação de Curitiba contribuíram ou não para a valorização dos profissionais em questão, relacionado com a política educacional. Durante o estudo foram analisados processos judiciais em que são discutidos os diferentes aspectos da vida funcional dos servidores do magistério municipal de Curitiba. O trabalho foi organizado observando as seguintes etapas: discussão sobre o papel do Estado e os profissionais do magistério; mobilização dos profissionais do magistério de Curitiba por meio da Associação do Magistério Municipal de Curitiba e Sindicato do Magistério Municipal de Curitiba; evolução legislativa no Município de Curitiba no tocante aos profissionais do magistério; concepções de valorização profissional do magistério; análise dos pedidos, contestações e decisões nos processos judiciais individuais ou coletivos ajuizados por meio do departamento Jurídico do SISMMAC e análise do impacto que essas decisões tiveram na vida dos profissionais do magistério de Curitiba. Ao final da pesquisa concluiu-se que muitas decisões procedentes ou improcedentes impactaram positiva, mas também negativamente, na valorização dos profissionais do magistério, e que muitas das conquistas poderiam ter sido obtidas também pela mobilização. É conclusão ainda que a valorização profissional decorre da mobilização dos trabalhadores e que os processos judiciais são instrumentos para fortalecer a mobilização, mas que por si só não asseguram a plena valorização.

Palavras-chave: Profissionais do magistério; Docentes; Decisões judiciais; Valorização Profissional; Sindicato; Judicialização. 


\title{
RESUMOS DE TESES E DISSERTAÇÕES
}

\section{Um panorama da remuneração inicial dos professores nos municípios do primeiro anel metropolitano de Curitiba: configurações, impasses e perspectivas}

\author{
Autora: Juliana Aparecida Alves Subirá \\ Nível: Mestrado em Educação (PPGE/UFPR) \\ Orientadora: Dra. Andréa Barbosa Gouveia
}

A presente investigação tem como objeto de estudo a remuneração dos professores no magistério público frente às políticas educacionais nacionais e municipais, desde a implantação do Fundo de Manutenção e Desenvolvimento do Ensino Fundamental e de Valorização do Magistério (FUNDEF), em 1996, até o ano de 2010. Para abordar este objeto de estudo, fez-se necessário um breve resgate histórico do tratamento da remuneração no magistério público, nos limites da premência desta dissertação e dos mecanismos legais, desde o Brasil Colônia até a determinação da lei que estabelece o Piso Salarial Profissional Nacional (PSPN) aos professores. O objetivo é analisar se os arranjos das políticas educacionais alteraram ou alteram as condições da remuneração inicial dos professores da rede pública municipal no primeiro anel da região metropolitana de Curitiba e seus efeitos. Para a tarefa, foram coletadas em prefeituras e sindicatos informações sobre a remuneração inicial dos professores de ensino fundamental da rede municipal, dados que foram disponibilizados em tabelas salariais e na forma de leis municipais. Em posse dos dados, foi possível a construção do panorama da remuneração inicial dos professores na região metropolitana de Curitiba no período proposto por esta investigação. Da análise destes dados, aliada ao contexto socioeconômico dos municípios, são pontuadas algumas considerações da configuração da remuneração inicial dos professores do magistério público na região metropolitana de Curitiba, que podem não somente desvelar a remuneração inicial e suas condições como balizar a luta dos profissionais da educação no contexto da política educacional.

Palavras-chave: Políticas educacionais; Remuneração inicial dos professores; Região metropolitana. 


\title{
RESUMOS DE TESES E DISSERTAÇÕES
}

\section{Políticas de educação especial no ensino médio público paranaense: 0 aluno com deficiência em foco}

\author{
Autora: Ana Paula de Carvalho \\ Nível: Mestrado em Educação (PPGE/UFPR) \\ Orientadora: Profa. Dra. Laura Ceretta Moreira
}

Este estudo buscou, principalmente, elucidar como os alunos com deficiência física, intelectual, visual (cegueira/ baixa visão), múltipla e auditiva, com surdez e surdocegueira, matriculados no ensino médio, têm sido contemplados pelas políticas de educação especial. Sendo assim, intentou-se analisar textos normativos publicados em âmbito nacional e no Paraná, sobretudo a partir da década de 1990, que tratam da educação especial e do ensino médio. Para tanto, em um primeiro momento, foram apresentadas considerações sobre a trajetória histórica da educação especial e do ensino médio no contexto legislativo brasileiro, sendo que também foi possível realizar uma breve retomada sobre esse histórico, considerando-se, especificamente, o contexto paranaense. Para a análise dos textos normativos publicados em âmbito nacional e no Paraná, sobretudo a partir da década de 1990, os seguintes indicadores de análise foram elencados: $\left(1^{\circ}\right)$ Conceituação/ concepção do ensino médio e da educação especial; (2) População-alvo do ensino médio e da educação especial nos documentos; ( $3^{\circ}$ ) Serviços de educação especial, com a intenção de perceber, principalmente, as garantias de acesso e permanência do alunado com deficiência no ensino médio, sendo necessário transitar por campos como as previsões específicas para o ensino fundamental e para as instituições especializadas. Também, realizou-se uma análise dos Microdados do Censo Escolar (2007, 2008 e 2009) disponibilizados pelo Ministério da Educação / Instituto Nacional de Estudos e Pesquisas Educacionais Anísio Teixeira, na qual se buscou elucidar como está ocorrendo o acesso e a permanência de alunos com deficiência do ensino fundamental ao médio, considerando-se dados nacionais e paranaenses por rede de ensino. Observou-se que a educação especial e ensino médio têm marcas de uma democratização tardia que permeiam até hoje a conceituação/ concepção dessa etapa e modalidade da educação básica. Os Microdados analisados também revelaram uma descontinuidade nos estudos dos alunos com deficiência do ensino fundamental ao médio, principalmente quando se considera os primeiros anos do ensino fundamental, ocasionando um baixo número de alunos com deficiência que chega a ingressar no ensino médio. Esse quadro é ainda mais excludente quando são considerados os dados paranaenses. Assim, em síntese, foi possível perceber que ensino médio tem debilidades próprias até mesmo no plano normativo e que essas ocasionam reflexos particulares quando considerados os alunos com deficiência.

Palavras-chave: Educação Especial. Ensino Médio. Paraná. Políticas Educacionais. 


\title{
RESUMOS DE TESES E DISSERTAÇÕES
}

\section{Planejamento orçamentário e os recursos para a educação: um estudo sobre as leis de diretrizes orçamentárias (Idos) dos municípios do primeiro anel metropolitano de Curitiba}

\author{
Autora: Simony Rafaeli Quirino \\ Nível: Mestrado em Educação (PPGE/UFPR) \\ Orientadora: Dra. Andréa Barbosa Gouveia
}

O presente trabalho tem como objetivo analisar o tratamento oferecido ao tema da educação nas Leis de Diretrizes Orçamentárias (LDOs) dos municípios que compreendem o primeiro anel metropolitano de Curitiba, nos anos 2001, 2006, 2007 e 2009. Para isso, verifica, inicialmente, como ocorre a apresentação das metas para a educação nestas leis, procurando observar as mudanças introduzidas durante os anos analisados e o tratamento oferecido as mesmas, bem como evidenciar se as LDOs foram sendo aprimoradas no que se refere à transparência desses dados. Em seguida, realiza a análise das metas planejadas para a Educação Infantil e para o Ensino Fundamental - séries iniciais, por meio de categorias (merenda, transporte, imóveis, infraestrutura, ações, programas, convênios, profissionais da educação e materiais didáticos e afins), procurando demonstrar as diferenças e as semelhanças no tratamento dessas metas nos anos correspondentes ao período do FUNDEF (2001 e 2006) e nos anos referentes ao período do FUNDEB (2007 e 2009). Além disso, seleciona dois municípios que apresentam formas distintas de tratamento das metas para a educação para serem analisados de forma mais detalhada por meio de entrevistas com os responsáveis pela elaboração das LDOs. Pode-se afirmar que as metas para a educação são organizadas nestas leis de diferentes formas e que existem alguns problemas na apresentação das mesmas, dificultando o seu acompanhamento. Por outro lado, verificou-se uma agenda educacional dos municípios no que se refere a algumas metas e observou-se em alguns municípios a preocupação com a captação de recursos extras, cuja fonte principal de recursos indicada foi o FNDE por meio de seus programas. No que se refere aos efeitos da política de fundos na definição destas metas, observou-se que o FUNDEF provocou pouco impacto, pois a focalização do Ensino Fundamental limitou-se a poucas metas, não houve priorização apenas dos profissionais do magistério no que se refere à capacitação, apenas um município previu meta de capacitação para professores leigos, poucos municípios previram metas relacionadas aos conselhos do FUNDEF e não houve o planejamento de metas relacionadas à valorização salarial dos professores. O mesmo acontecendo nas LDOs referentes ao período do FUNDEB, pois apesar de verificarmos a predominância de metas para ambas as etapas e o planejamento de metas relacionadas à capacitação dos profissionais da educação, apenas um município apresentou meta de planos de carreira, poucos municípios apresentaram metas de convênios para a Educação Infantil e não houve o planejamento de metas relacionadas à valorização salarial dos professores e aos conselhos do FUNDEB. Também não se observou diminuição de metas nos anos em que alguns municípios perderam recursos com os fundos. A análise dos casos específicos nos permitiu verificar que o processo de elaboração das LDOs precisa ser aberto à participação popular e no caso da definição de metas para a educação, principalmente, ao CACS FUNDEB. Além disso, nos faz enfatizar a necessidade dos municípios do primeiro anel metropolitano atualizarem seus sites e disponibilizarem as LDOs juntamente com seus anexos, o que facilitará o controle social e a realização de futuras pesquisas envolvendo as LDOs como fonte de dados.

Palavras-chave: Planejamento Orçamentário. Lei de Diretrizes Orçamentárias. Metas para a educação. Recursos para a educação. 